\title{
Corrigendum: Balancing research and funding using value of information and portfolio tools for nanomaterial risk classification
}

Matthew E. Bates, Jeffrey M. Keisler, Niels P. Zussblatt, Kenton J. Plourde, Ben A. Wender and Igor Linkov

Nature Nanotechnology 11, 198-203 (2016); published online 9 November 2015; corrected after print 4 February 2016.

In the version of this Article originally published, the data in Figs 1b-e and 2 were incorrect because of a coding error in the Monte Carlo analysis; the figures have now been replaced. Supplementary Figs 1-3 and Tables 1-7 also relied on these calculations and have been replaced. Furthermore, in the caption to Fig. 1e inset and in the related sentence in the main text, the values discussed were incorrect and have now been amended. None of these changes affect our conclusions. These errors have been corrected in the online versions of the Article. 